\title{
A produção escrita em inglês como língua estrangeira através do ensino de gêneros discursivos: $A$ análise de uma lição
}

\author{
Isabela Gomes Bustamante \\ PUC-Rio
}

O ensino da escrita em inglês como língua estrangeira através dos gêneros discursivos oferece ao aprendiz o acesso a textos com os quais ele possivelmente terá contato ao longo da sua vida pessoal, profissional ou acadêmica. Cope e Kalantzis (1993) acrescentam que o ensino de gêneros não deve ser feito de forma a reproduzir um modelo, mas sim para "(...) dominar um instrumento que encoraje o desenvolvimento e a mudança mais do que a simples reprodução". No caso de um curso de inglês onde alunos têm motivações e interesses diferentes, torna-se mais desafiador encontrar gêneros que satisfaçam a todos os alunos. O objetivo deste trabalho é investigar a pertinência de uma lição para o ensino da escrita em inglês do gênero Carta de Reclamação através da sua análise e da produção escrita de cinco alunos à luz dos conceitos do Ciclo Sistêmico de Ensino e Aprendizagem da Lingüística Sistêmico-Funcional da Austrália.

Palavras-chave: discurso escrito, gêneros discursivos, andaimento

\section{INTRODUÇÃO}

Atualmente, não é raro ouvir as pessoas justificarem sua opção por estudar inglês como língua estrangeira por ser este idioma fundamental para se obter uma boa colocação no mercado de trabalho ou para poder se comunicar em situações de viagem, sejam elas a trabalho ou como turistas. A tendência atual tem demonstrado que é com freqüência que um indivíduo, ao se dirigir à secretaria de um curso de inglês, apresenta as seguintes dúvidas: em quanto tempo ele estará apto a falar nesse idioma fluentemente, se o curso oferece aulas só de conversação, se "ainda se ensina gramática" (pois ele tem como crença que o ensino de gramática pode prejudicar o foco na conversação), entre outras. Esses questionamentos e interesses com relação ao aprendizado da língua inglesa refletem a necessidade do indivíduo de adquirir a habilidade de se expressar oralmente em inglês dentro do menor tempo possível para corresponder às demandas do meio profissional 
como, por exemplo, participar de entrevistas de emprego em inglês ou falar ao telefone com mercados externos, e também para fazer parte ativamente do mundo globalizado.

Visando a corresponder às expectativas do aluno e a se enquadrar nesta nova realidade, os cursos de idiomas, em geral, têm priorizado as atividades em sala de aula que envolvam conversação, dando menor ênfase ao desenvolvimento das habilidades escritas. Com o argumento de que é importante aproveitar o tempo em sala de aula para estimular a conversação em inglês e desenvolver a habilidade oral, os professores deixam as tarefas escritas para serem feitas pelo aluno em casa o que, como conseqüência, reflete-se na falta de interesse e motivação do aprendiz para desenvolver suas habilidades escritas em língua inglesa, a não ser que a motivação seja receber do professor uma nota para ser aprovado.

A implementação da abordagem comunicativa, a partir dos anos setenta, estimulou os cursos de inglês e professores a fazerem uso de diversos recursos e estratégias de ensino que trouxessem para o ambiente de sala de aula situações espontâneas do uso da língua inglesa, em que os aprendizes pudessem aprender e praticar o idioma o mais próximo possível das situações reais da vida cotidiana, profissional ou acadêmica. Entre essas estratégias de ensino com base na abordagem comunicativa, houve a preferência pelo uso de materiais autênticos em sala de aula em detrimento dos materiais feitos para fins educacionais. Entende-se por materiais autênticos exemplares de determinado gênero que foram produzidos com o propósito de serem utilizados em certas situações da vida cotidiana e não para o ensino, como, por exemplo, receitas extraídas de livros de receita, cardápios de restaurantes, cartas de reclamação escritas com este propósito, em uma situação real, entre outros. Assim como o material didático, o uso de materiais autênticos oferece aos aprendizes uma diversidade de gêneros discursivos; no entanto, os materiais autênticos propiciam e estimulam a interação e a comunicação a mais próxima possível dos usos reais da língua inglesa.

Neste trabalho, busco refletir criticamente sobre a noção de gêneros discursivos e o ensino da escrita em língua inglesa em cursos de idiomas através da análise de cinco produções escritas de aprendizes sobre o gênero carta de reclamação (Figuras 3 A-E). A produção destas redações foi o último estágio de uma aula que é analisada neste trabalho à luz do Ciclo Sistêmico de Ensino e Aprendizagem, proposto e elaborado por pesquisadores australianos que seguem a teoria da lingüística sistêmico-funcional (Figura 1). Em seguida, 
procuro discutir se a produção destes aprendizes refletiu o aprendizado em sala de aula com base no gênero.

Na primeira parte do trabalho, faço uma revisão dos estudos de Bakhtin (1992), Swales (1990) e Bhatia (1999) sobre gêneros discursivos ou textuais, de Halliday e Hasan (1989) sobre o papel do leitor na co-construção do sentido de um gênero e de Cope e Kalantzis (1993) sobre a produção criativa de gêneros; em seguida, descrevo o corpus do trabalho e os critérios de análise. Como parte destes critérios, abordo os conceitos sugeridos pelo Ciclo Sistêmico de Ensino e Aprendizagem. Logo a seguir, apresento o estudo propriamente dito, analisando as redações à luz deste Ciclo e do ensino através dos gêneros. A seguir, apresento as minhas conclusões sobre a análise e discuto a pertinência da minha hipótese, que é investigar a relevância de outras atividades e gêneros propostos pelo professor e pelo plano de aula de curso de inglês para auxiliar na produção escrita do gênero cartas de reclamação. Para concluir, aponto algumas sugestões para pesquisas futuras.

\section{Gêneros discursivos e o ensino da escrita em língua inglesa}

Os gêneros discursivos surgem nos processos sociais e são elaborados com fins específicos, com forma e conteúdo relativamente definidos, para serem compreendidos por indivíduos que compartilham determinado conhecimento acerca dos mesmos, por fazerem parte da mesma "comunidade discursiva" (Swales, 1990). Para Bakhtin (1992:301), o indivíduo primeiro define o seu propósito, para então decidir o gênero que vai usar.

Segundo Swales, ao fazer parte de determinada comunidade discursiva que produz e/ou lê exemplares de determinado gênero, o indivíduo pode reconhecer uma produção como parte de um gênero e não de outro. Entretanto, isto não significa que todos os exemplares do mesmo gênero tenham as mesmas características quanto à forma e ao conteúdo, mas sim que há algo em comum entre estes exemplares que faz com que o indivíduo o reconheça como determinado gênero. Essa variedade entre espécies do mesmo gênero deve-se tanto à criatividade de quem o produziu como à flexibilidade de alguns tipos de texto, o que talvez faça com que o mesmo mude e adquira uma outra opção de formato, o que se alinha ao pensamento de Bhatia (1999), um expoente do grupo de inglês para fins específicos (ESP), quando este argumenta que gêneros discursivos são dinâmicos 
apesar de serem estáveis. Segundo esta perspectiva, a última etapa no conhecimento de um gênero é saber interpretar, usar e modificá-lo, manipulando-o de acordo com a finalidade ou intuito discursivo (Bakhtin, 1992:300). No entanto, por pertencer à comunidade discursiva e não ao indivíduo, os gêneros não são criados por um indivíduo, mas sim pelo coletivo, então, essa escolha não é livre (Bakhtin, 1992:304).

Em alguns casos, o leitor é capaz de identificar determinado gênero textual por pertencer a uma comunidade discursiva determinada que compartilha conhecimentos, culturas e contextos específicos que possibilitam tal identificação (Swales, 1990). Isto significa que o leitor não tem um papel passivo diante do gênero, pois este só pode ser identificado como tal porque o leitor ativamente co-construiu o sentido do texto através do seu conhecimento de mundo e das suas inferências durante o processo de leitura. De acordo com Halliday e Hasan, isto ocorre porque

A situação onde a interação ocorre fornece aos participantes uma grande quantidade de informações sobre os significados que estão sendo trocados, e os significados que são passíveis de serem trocados. E o tipo de descrição ou interpretação do contexto da situação que será o mais adequado para o linguista é o que o caracteriza naqueles termos, isto é, nos termos que permitem que ele ou ela faça previsões sobre estes significados, de modo a ajudar a explicar como as pessoas interagem. (1989:10.) (Tradução minha.) ${ }^{1}$

Ao escrever um texto que siga ou não as convenções de um gênero, o escritor deve ter em mente o que ele sabe a respeito do gênero em si e a respeito da pessoa que lerá o seu texto. Bakhtin afirma que "quando se subestima a relação do locutor com o outro e com seus enunciados (existentes ou presumidos), não se pode compreender nem o gênero nem o estilo de um discurso" (1992:324).

No entanto, algumas questões podem ser discutidas a respeito do uso de gêneros discursivos para fins pedagógicos como, por exemplo, o uso de determinado gênero como modelo. Mesmo que o propósito do professor seja apresentar o gênero ao aluno, é provável

\footnotetext{
${ }^{1}$ The situation in which linguistic interaction takes place gives the participants a great deal of information about the meanings that are being exchanged, and the meanings that are likely to be exchanged. And the kind of description or interpretation of the context of situation that is going to be most adequate for the linguist is one that characterizes it in those terms: that is, in terms that enable him or her to make predictions about the meanings, of a kind that will help to explain how people interact. (Halliday e Hasan, 1989:10)
} 
que este, principalmente se for de nível iniciante, utilize o gênero como modelo para produzir o seu próprio texto e acabe fazendo isto de forma automática e mecânica. Segundo Bakhtin (1986:80), para produzir um gênero de forma criativa, o escritor deve ter pleno domínio deste gênero. Cope e Kalantzis (1993) acreditam que o ensino de gêneros não deve ser feito de forma a reproduzir um modelo, mas sim, para “(...) dominar um instrumento que encoraje o desenvolvimento e a mudança mais do que a simples reprodução".

Com base nessas teorias sobre gêneros discursivos, descrevo, a seguir, o contexto da pesquisa e a pesquisa propriamente dita.

\section{$O$ contexto da pesquisa}

As redações que compõem o corpus deste trabalho foram produzidas por aprendizes adultos que se encontram no último ano do ciclo intermediário de curso de inglês como língua estrangeira localizado na cidade do Rio de Janeiro. Os alunos cursam o terceiro ano e têm objetivos diferentes uns dos outros com relação ao aprendizado do idioma, como por exemplo, aprender inglês para se comunicar em viagens de turismo, para ter um certificado de conhecimento da língua para agregar valor ao currículo, para fazer entrevistas de emprego, para se comunicar com clientes estrangeiros, para ler livros em inglês, entre outros.

O material didático adotado nesse nível é produzido pela editora do próprio curso de inglês onde os alunos estudam e visa a atender às necessidades do aprendiz brasileiro. Esse material didático inclui livro-texto e de exercícios no mesmo volume, $\mathrm{CD}$ com atividades e com áudio para os alunos ouvirem em casa, a transcrição dos textos com áudios ouvidos em sala de aula, fichas com um resumo de cada ponto gramatical abordado em cada unidade, dois livros para o professor (um livro-texto e outro com os planos de aula para cada unidade e com atividades extras para serem fotocopiadas e trazidas para a sala de aula), vídeos didáticos e vídeos com trechos de produções cinematográficas com atividades a serem implementadas antes, durante e após a exibição dos mesmos, e atividades em flash (animação) no computador da sala de aula. Os textos que compõem o livro-texto, ainda que possuam temas bastante atuais, não são autênticos, mas sim textos elaborados pelos autores do próprio material didático. 
Cada módulo do curso tem a duração de um semestre e as aulas ocorrem duas vezes por semana, com duração de noventa minutos. O curso tem como objetivo desenvolver quatro habilidades lingüísticas no aprendiz: compreensão auditiva, fala, leitura e escrita do idioma inglês. Portanto, o professor, em noventa minutos, deve implementar atividades que visam a atender o desenvolvimento dessas habilidades. A habilidade escrita, na maioria das vezes, é desenvolvida em casa, através de exercícios e redações com temas propostos no próprio livro-texto, e é o último estágio da lição.

A produção das redações que compõem o corpus deste trabalho foi o último estágio de uma aula cujo foco era capacitar o aluno a escrever um e-mail de reclamação em inglês através do aprendizado de expressões utilizadas em situações de reclamação, tais como too cold, not fast enough, entre outras.

\section{Procedimentos de análise}

Este trabalho visa a analisar uma aula para adultos de nível intermediário de curso de inglês como língua estrangeira que tem como objetivo capacitá-los a escreverem o gênero "e-mail de reclamação". A análise está baseada no "Ciclo Sistêmico de Ensino e Aprendizagem" (Figura 1), segundo a proposta do LERN, Literacy and Education Research Network, elaborado e desenvolvido por alguns pesquisadores australianos, expoentes da Lingüística Sistêmico-Funcional no final dos anos 80, entre eles Gunther Kress, Mike Callaghan, Mary Kalantzis, Jim Martin, Bill Cope, Anne Cranny-Francis e Diana Slade.

\section{O Ciclo Sistêmico de Ensino e Aprendizagem}

O objetivo do Ciclo Sistêmico de Ensino e Aprendizagem (Figura 1) é auxiliar os aprendizes no processo de escrita de determinado gênero em língua estrangeira desde a elaboração do contexto do texto até a produção autônoma desse gênero, passando pela apresentação e discussão de amostras do mesmo gênero. Durante todo esse processo, o aprendiz tem acesso ao contexto cultural e social do texto, sua estrutura, seu conteúdo e seus atributos lingüísticos. Espera-se que o ciclo seja usado com flexibilidade, e que "os professores sejam encorajados a entrarem no ciclo em qualquer estágio, de acordo com as necessidades dos alunos" (Hammond et al., 1992:17). 
Através da noção de andaimento ("scaffolding"), os alunos, primeiramente, são auxiliados pelo professor a construírem seu pensamento sobre o gênero e a produzi-lo; depois, os alunos dão continuidade ao processo de forma autônoma. Trabalhos mais recentes (por exemplo, Donato, 2000; Ohta, 2000) têm demonstrado que, no processo de andaimento, a construção do conhecimento pode ser auxiliada não apenas pelo professor, mas também pelos colegas através da interação. Segundo Paltridge, "embora deva levar mais tempo para o professor implementar o andaimento, há evidências de que esse tempo é bem gasto" ${ }^{2}$ (2001:33) (tradução minha).

Figura 1. Ciclo Sistêmico de Ensino e Aprendizagem

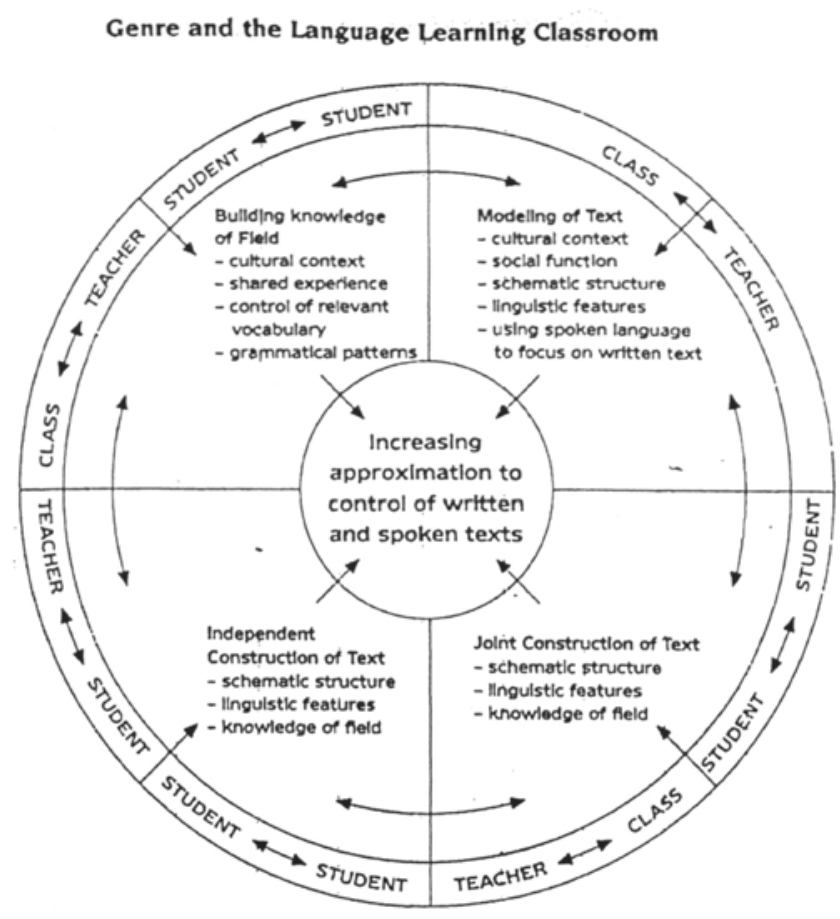

The systemic teaching and learning cycle. (From Hammond et al. 1992, 17.)

\section{O estudo}

As seis atividades iniciais propostas pelo livro enquadram-se no estágio "Construindo o conhecimento acerca do tópico (field)", que, segundo o Ciclo, podem envolver professor e alunos ou apenas os alunos.

\footnotetext{
${ }^{2}$ Although it may take more time to a teacher to scaffold, there is evidence that it is time well spent. (Paltridge, 2001:33)
} 
A primeira atividade sugere que os alunos respondam, em grupos, a três perguntas pessoais sobre o uso de e-mails e a freqüência com que eles recebem e respondem a spams, que são e-mails indesejados como propagandas, correntes ou piadas. Essa atividade está em alinhamento com a proposta desse estágio do Ciclo, estágio esse em que alunos e professores constrõem o conhecimento a respeito do contexto cultural, trocam experiências e adquirem vocabulário relevante para o tópico. Nesse estágio da aula, os alunos são encorajados a refletir sobre o tema "e-mail de reclamação", já que eles devem conversar com seus colegas sobre $e$-mails indesejados.

Na segunda atividade, os alunos devem ler o gênero "anúncio" que aparece em uma “janela pop up da Internet”, e devem encontrar as palavras e expressões nesse anúncio de acordo com as suas definições presentes no livro. É importante ressaltar que esse anúncio não é um texto autêntico, mas sim produzido pelos autores do livro didático. Essa atividade também faz parte do estágio "Construindo o conhecimento acerca do tópico (field)", pois ela proporciona um controle do vocabulário relevante para o nível e para a lição.

A terceira e a quarta atividades têm como foco trabalhar a compreensão auditiva dos aprendizes. Primeiro, eles devem ouvir um diálogo em um CD, produzido pelos autores do livro, e fornecer duas informações específicas a respeito do diálogo. Nessa atividade, o tema "reclamação" é inserido explicitamente, já que a resposta a ser dada pelo aluno para a pergunta "Por que o Steve está telefonando para o Yoohooh.com?" é "Para reclamar a respeito do serviço". Nessa atividade, o gênero "ligação telefônica para fazer uma reclamação" é exemplificado com a participação dos alunos e, por isso, ela pode ser inserida em outro estágio do Ciclo Sistêmico de Ensino e Aprendizagem, que é o "Modelando o texto", no qual alunos e professor trabalham o contexto cultural do texto e sua função social. Na quarta atividade, os alunos devem ouvir o diálogo novamente, dessa vez lendo a transcrição no livro. Individualmente, eles devem responder quais os dois problemas com o serviço que foram reclamados pelo Steve. Essa atividade também está inserida no mesmo estágio, pois eles estão se baseando em um modelo de diálogo envolvendo reclamação.

A quinta atividade sugere que os alunos reproduzam o diálogo do CD. Antes de fazê-lo, eles devem anotar, no livro, ao lado do diálogo, duas ou três palavras-chave ou as mais difíceis de cada turno que possam ajudá-los a se lembrar do diálogo depois. O papel 
do professor nessa atividade é auxiliá-los com a pronúncia e o significado das palavras e dos enunciados. Após comparar suas escolhas com as do colega ao lado, eles devem cobrir o diálogo e tentar reproduzi-lo, apenas olhando as palavras escritas por eles. Durante a reprodução do diálogo, o professor, segundo o plano de aula, deve monitorar a atividade, ajudando e elogiando os alunos sempre que possível. Essa atividade também se insere no estágio "Modelando o texto", pois os alunos aprendem e praticam a estrutura esquemática do gênero e, segundo o Ciclo, "utilizam a língua falada para focalizar no texto escrito".

Os atributos lingüísticos mencionados no estágio "Modelando o texto" são trabalhados na sexta e na sétima atividades do livro, nas quais os alunos aprendem e podem praticar as expressões utilizadas para fazer uma reclamação. Antes da sexta atividade, o livro apresenta algumas expressões utilizadas para fazer uma reclamação. Na atividade seis, os alunos devem completar seis frases que expressam reclamações com as expressões extraídas da tabela onde o vocabulário é apresentado. A sétima atividade pode ser feita em grupos e sugere aos alunos que eles relacionem seis frases de reclamação de acordo com os lugares onde elas poderiam ocorrer. Também dentro do estágio "Modelando o texto", essas atividades proporcionam aos alunos trabalhar "o contexto cultural, a função social, a estrutura esquemática e os atributos lingüísticos".

Antes da oitava atividade, os alunos fazem uma prática controlada de um diálogo de reclamação apresentado no computador da sala de aula, em flash, e praticam o diálogo em pares. Esta prática controlada também faz parte do estágio "Modelando o texto".

$\mathrm{Na}$ oitava atividade do livro, o gênero "diálogo envolvendo reclamação" pode ser produzido pelos alunos, em duplas, e deve ser baseado em um dos cinco lugares apresentados no exercício anterior. O manual do professor sugere que os alunos escrevam o diálogo em dupla antes de praticá-lo, mas deixa claro que o foco dessa atividade é a fluência oral, já que eles vão trabalhar a escrita mais à frente. Além disso, o manual do professor afirma que este deve mostrar ao aluno que eles estão sendo capacitados a produzirem esse gênero em outras situações da vida real além da apresentada no modelo. Essa atividade faz parte do estágio "Construção do texto em conjunto" do Ciclo e, de acordo com o mesmo, visa a trabalhar a estrutura esquemática, os atributos lingüísticos e o conhecimento sobre o tópico. 
Todas as atividades até então têm como objetivo preparar os alunos para o foco principal da aula, que é capacitá-los a escrever um e-mail de reclamação. A escrita será trabalhada explicitamente nas atividades nove e dez. Segundo o manual do professor, os alunos devem, primeiramente, observar e descrever a foto que aparece ao lado dessas atividades, na qual um rapaz está a frente de um computador. O professor deve, também sobre a foto, perguntar aos alunos qual problema deve estar ocorrendo e pedir que eles leiam o texto escrito no livro e completem as lacunas com as expressões da atividade nove. Esse texto é um modelo, não autêntico, de um e-mail para fazer reclamação e, ao completálo com determinadas expressões, os alunos estão "ajudando a construir o texto", de uma forma bastante controlada, que é outro estágio do Ciclo, em que os alunos aprendem a estrutura esquemática, os atributos lingüísticos do gênero "e-mail" (linguagem formal, texto curto e objetivo) e o conhecimento acerca do tópico, quando o professor pede que a foto seja analisada. A última atividade refere-se ao estágio "Construção independente do texto", na qual os alunos, em casa, deverão, segundo o livro, imaginar um problema em um dos lugares citados no exercício sete e escrever um e-mail para reclamar.

Seria desejável que os textos apresentados nessa aula fossem autênticos, pois os alunos estariam tendo acesso a modelos reais e não criados especificamente para essa lição. Por outro lado, o modelo não-autêntico possibilita ao aluno ter acesso, exclusivamente, ao vocabulário e às estruturas gramaticais desejáveis e apropriadas para o seu nível de inglês e, conseqüentemente, o aprendizado do gênero pode ser trabalhado de maneira mais controlada, como sugere o Ciclo, predominando, então, o objetivo pedagógico com controle.

Segundo o manual do professor, o aluno deve produzir o gênero, em casa, com base no modelo do exercício nove. Como pode ser depreendido após a leitura das cinco redações apresentadas neste trabalho (Figura 2), os alunos realmente seguiram o modelo proposto no livro e todos, sem exceção, copiaram algumas expressões e estruturas, principalmente o início de cada parágrafo. 
Figura 2. Cinco aberturas das Cartas de Reclamação produzidas pelos alunos de nivel intermediário.

Dear Sir or Madam.

I'm whithing to complain about the service you proveide at your restauront. I'm not veref satis. fiel I vias thice in thes moming.

Dear Sir or Madom,

I'm writing to complain about the surcice you pravide at your Japonese mestaurant. I was there yes urda and I wasn't vrus satiofied about the waiter's senvice

Dear Moncela.

I'm writing to complaim abat the service you provide at your restarant. I was there yesterdoy and I wasn't bery sotesfeed.

Dear ser or madam

I'm wrting to complain about the serrece of my telerision. I boubht my, TV with You for 2 momths, and

Dear Sir ore Hadam,

I'll writing to complaint about the service iri your restaurant. I was there today ir the at ternon to have lunch and I wasn't very satistid. 
No entanto, não é possível afirmar que eles reproduziram o gênero mecanicamente, visto que eles criaram a situação e produziram reclamações diferentes uns dos outros. É interessante observar que os cinco alunos reproduziram a estrutura retórica do gênero de forma eficaz, incluindo a descrição da situação, quando ela ocorreu, a reclamação em si e as providências que eles esperam que sejam tomadas. Vejamos a seguir os textos dos alunos A, B, C, D, E.

Aluno A:

- Composition ALO page 25 Exciresse so.

Dear Sir or Madam,

I'm writing to complain about the sevice you yprevide at your restauront. I'm not werey seatis. fiect. I vias thire in the moming.

To stint with, the wutlery ond vide plate are disty and brokin. And the attendonce is too slor winci bad, there were too many people for tac Hifibit woutins. Also the faod is not enough, not hot and very elepansibe

I sepect you to greer me a xefernol other wise - ther lunch that are releable enoxigh, and that are free Yours fouthfuller, 
Aluno B:

Compositions:

Book - Page: $25(E x, 9)$

Dear sir or Madom,

I'm writing to complain about the sercice you praride at yair Japonese nestaurant. I was there yesurdas and I wasn't very satisfied about the waiter 's senvice

to start with, the poad was ury slaw, and muer goes what I asked. Also, the waitirs are so runde with us. It was a complete waste of my time and. monuy.

- I expect yae to apive me a pre dinner, otherwise I mever converck at your restaurant. yours faith pulles, 
Aluno $C$ :

Dear Moncila

I'm wuting to complaim abat the service

you provide at your restarant. I was there yenterdoy

and I wasn't very sotisfeed.

Funst of all, it took me a lomg time to get

a toble becouse there were too many people

and mot ensugh table for everybody. Also, Whem

I was funally able to rit down, I spernt thirty

menutes for the water. Ok! I'm not umploining

alout this bet, becouse the restawnont was full.

But when I was eating. I found a piece of

mir in my trod. It was a tirride experience?

I expect you gire rine a refund.

XXX

Aluno D:

Dear ser or madam

I'm wreting to complain about the servece of my

telerision. I bought my, IV with You for 2 momits, and

It's bad, I don't meed change the channel, I don't meed

decuase, incuase, my TV is Terrible. I would you like, that You change for me it takes me expensive, if you don't change for me, I would You like that You give me a refund.

Yours fouthfully

$x \times X X$ 
Aluno E:

to: manague@ the buxtrestaurant.com

subject: complaining

Dear Sir ore Hadam,

I'll writing to complaint about the service iri your restaurant. I was there today iri the atternon to have lunch and I wasn't very satistid.

To start with, I was waiting a lot of time to obtaun a table. Also my tood delayed to arrive and was cold. It's unacceptave toi a good restaweant with your tradition

I expect you to grve me a retund, o therwesi I'le have to take tuther action

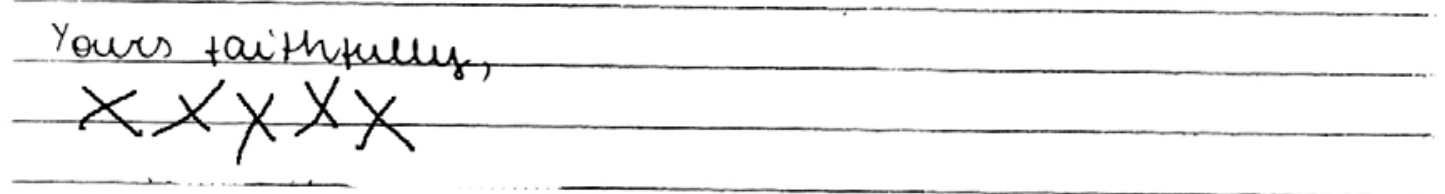

Em síntese, a aula em análise alinhou-se à abordagem de ensino proposta pelo Ciclo Sistêmico de Ensino e Aprendizagem, pois os alunos puderam, através do processo de andaimento, passar do estágio em que eles eram altamente dependentes do professor para o estágio em que se espera que o professor seja apenas o facilitador do processo à medida que os alunos passam a ter maior competência lingüística.

Os aprendizes da aula em estudo foram encorajados a participar do processo de forma ativa através da troca de opiniões sobre o tema e seu contexto, da feitura dos exercícios e da redação final. Além disso, eles foram monitorados pelo professor durante a 
aula e puderam ter acesso a um modelo do gênero em foco e, após o seu breve estudo, puderam produzir um texto do mesmo gênero, sozinhos. Pode-se dizer que o resultado desse aprendizado em específico foi satisfatório, pois, mesmo estando os alunos trabalhando com material didático e não-autêntico e mesmo copiando determinadas estruturas, eles, de certa forma e, principalmente para o seu nível, intermediário, foram capazes de escrever um e-mail para reclamar de um serviço ou um produto adquirido. Ainda que de forma limitada, eles produziram o gênero de forma criativa e bem próximo ao que seria produzido em uma situação real.

\section{CONSIDERAÇÕES FINAIS}

No mercado atual, onde a compra pela Internet de produtos estrangeiros como livros ou CDs, para citar apenas dois, é tão comum, é fundamental saber se expressar em inglês através da escrita para reclamar de um produto ou serviço que tenha apresentado algum problema. A função social desempenhada pelo gênero em estudo é viabilizar uma sociedade mais justa, onde o consumidor tenha pleno direito de reclamar de um produto ou serviço mal prestado. Ser capacitado a produzir esse gênero em inglês possibilita ao indivíduo a luta pelos seus direitos com a competência lingüística esperada, que pode lhe dar grandes chances de ser ouvido e respeitado.

$\mathrm{O}$ ensino da escrita em inglês como língua estrangeira através do ensino de gêneros discursivos não é garantia de sucesso no desempenho do aprendiz ao produzir esse mesmo gênero. Todavia, ao ter contato com o gênero, ao estudar a comunidade discursiva que o produz e que o lê, o propósito de produzi-lo, o aprendiz se familiariza com novas formas de organizar o espaço e o discurso na vida profissional, acadêmica ou pessoal. Além disso, o aluno pode ter contato com "uma gama de escolhas léxico-gramaticais em inglês e suas relações com os propósitos comunicativos em diferentes contextos e situações" (Santos, 2002:188).

Ao longo da aula analisada neste trabalho, os alunos engajaram-se em atividades variadas que permitiram que eles fossem co-construindo o conhecimento acerca do gênero, desde a primeira atividade, em que eles trocaram opiniões sobre o gênero "e-mail de reclamação" no estágio "Construindo o conhecimento acerca do tópico (field)". Esse 
estágio foi fundamental para contextualizar a aula e possibilitar que os alunos fizessem contribuições à aula com o seu próprio conhecimento de mundo sobre o gênero em estudo. O outro estágio, "Modelando o texto", mostrou-se relevante nesse ensino, principalmente por se tratar de uma turma iniciante, que necessita de um ensino mais explícito de gêneros para, no futuro, ser capaz de produzir textos de forma autônoma. Esse estágio da aula pode ser facilmente percebido nos textos escritos pelos alunos, pois há escolhas lexicais, gramaticais, estruturais e de conteúdo que seguem o modelo apresentado pelo livro-texto. Mesmo escrevendo sobre situações diferentes, os alunos produziram textos muito próximos ao texto apresentado no livro.

O estágio "Construção do texto em conjunto" possibilitou maior interação entre os alunos e troca de informações acerca do gênero. Nesse momento da aula, os alunos tiveram a oportunidade de iniciar o processo de criação de um diálogo cujo tema principal era "fazer uma reclamação", o qual, mais tarde, como continuidade, daria embasamento contextual, lexical e gramatical para o aluno escrever o e-mail. No estágio "Ajudando a construir o texto", os alunos aprenderam a estrutura retórica do gênero. Apesar de esse estágio ser, de certa forma, limitante sobre o gênero "e-mail de reclamação", podemos compreender, através deste estudo, que ele é pertinente por serem os alunos inciantes. Mesmo assim, seria interessante maior tempo de aula para o aluno ter acesso a vários outros exemplares desse gênero, para ele não ficar com apenas um modelo como referência. O que pôde ser visto nas redações foi que o modelo apresentado foi seguido de forma bastante fiel, o que é compreensível se for levado em conta o conhecimento léxico-gramatical dos alunos.

O último estágio, "Construção independente do texto", foi desenvolvido em casa, sem o auxílio dos colegas ou do professor, por isso ele é denominado de "independente". Acredita-se que, à medida que o aluno for adquirindo mais conhecimento sobre a língua inglesa, ele possa realmente "construir o seu texto independentemente", sem seguir um único modelo apresentado pelo professor, e inserindo características pessoais de estilo e conteúdo.

A proposta deste artigo foi analisar uma aula sobre o gênero "E-mail de Reclamação" com base no Ciclo Sistêmico de Ensino e Aprendizagem da Lingüística Sistêmico-Funcional. A análise desta aula mostra-se relevante para os estudos de gêneros 
discursivos, pois os gêneros ensinados com base na abordagem de andaimento proposta pelo Ciclo pode vir a capacitar o aprendiz a produzir textos em inglês de forma autônoma e criativa, pois ele é levado pelo professor a tornar-se independente ao longo do processo. Conseqüentemente, ao ter autonomia para escrever um gênero em inglês, o aluno adquire confiança e torna-se mais aberto e mais apto a aprender novos gêneros que também o ajudarão a compreender o mundo e a ser compreendido, tornando-se um aprendiz e cidadão melhor e mais independente.

\section{Sugestões para pesquisas futuras}

Seria interessante que um futuro estudo abordasse uma lição com foco também no gênero e-mail de reclamação e as produções escritas dos aprendizes, mas que oferecesse a eles exemplares autênticos do gênero em questão e em maior quantidade. Esses exemplares poderiam ser extraídos de seções de jornais em língua inglesa, como "Reclamação do Consumidor", ou da Internet. O professor poderia, inclusive, pedir que os alunos fizessem essa pesquisa na Internet para que eles já viessem à aula com esses exemplares e com algum conhecimento acerca do gênero em língua inglesa. Outra atividade seria o professor guiar a busca dos alunos, oferecendo-lhes endereços eletrônicos onde pudessem achar tais exemplares e atividades contendo o que eles deveriam pesquisar sobre o gênero: estrutura, conteúdo, tempo verbal, entre outros itens. Se o professor oferecer ao aluno diversos exemplares do mesmo gênero, o pesquisador poderá, então, verificar (1) se a produção escrita por eles sofre alguma interferência pelo fato de os modelos de gêneros serem autênticos ou não, e (2) se, ao terem acesso a um maior número de exemplares, os alunos passam a ser menos presos a estruturas léxico-gramaticais e de forma e (3) se conseguem dar maior dinamicidade ao gênero, produzindo-o ainda mais criativamente. $O$ estudo poderia ser feito também com uma turma iniciante para aprofundar a pesquisa iniciada neste trabalho. Em suma, poder-se-ia investigar o uso de materiais autênticos e nãoautênticos para o ensino do mesmo gênero, com o mesmo nível, e testar o uso de um exemplar contrastando-o com o uso de vários exemplares. 


\section{REFERÊNCIAS}

Bakhtin, M. (1986). The problem of speech genres. In C. Emerson \& M. Holquist (eds.) Speech Genres and other late essays (V. Mcgee, Trans., pp. 60-102). Austin: University of Texas Press.

(1992). Os gêneros do discurso. In M. Bakhtin. Estética da Criação Verbal 279-326. São Paulo: Martins Fontes.

Bazerman, C. (2005). Gêneros textuais, tipificação e interação. A. P. Dionísio \& J. C. Hoffnagel (orgs.) São Paulo: Cortez.

Berkenkotter, C. \& Huckin, T.N. (1995). Rethinking genre from a sociocognitive perspective. In Genre knowledge in disciplinary communication: Cognition/culture/power 1-25. Millsdale, N.J.: Lawrence Erlbaum.

Bhatia, V.K. (1999). Integrating products, processes, purposes, and participants in professional writing. In C.N. Candlin and K. Hyland (eds.) Writing: Texts, processes, and practices. London: Longman.

(2004). Worlds of written discourse: A genre-based view. London: Continuum.

Cope, B., \& Kalantzis, M. (1993). Introduction: How a genre approach to literacy can transform the way writing is taught. In: B. Cope \& M. Kalantzis (eds.) The powers of literacy: A genre approach to teaching writing 1-21. Bristol, PA: Falmer Press.

Donato, R. (2000). Sociocultural contributions to understanding the foreign and second language classroom. In J. Lantolf (ed.) Sociocultural theory and second language learning 29-52. Norwood, NJ: Ablex.

Halliday, M.A.K. \& Hasan, R. (1989). Language, context and text: Aspects of language in a socialsemiotic perspective. 2a. ed. Geelong, Vic: Deakin University Press. Oxford: OUP.

Hammond, J., Burns, A., Joyce, H., Brosna, D., \& Gerot, L. (1992). The pedagogical relations between adult ESL and adult literacy. Canberra: Commonwealth of Australia.

Hyon, S. (1996). Genre in three traditions: Implications for ESL. TESOL Quarterly, 30 (4), 693 722.

Johns, A.M. (2002). Introduction: Genre in the classroom. In A. M. Johns (ed.) Genre in the classroom: Multiple perspectives. Mahwah, N.J.: Lawrence Erlbaum.

Marcuschi, L.A. (2002). Gêneros textuais: Definição e funcionalidade. In A. P. Dionísio, A. R. Machado, \& M. Bezerra (orgs.) Gêneros textuais e ensino 19-36. Rio de Janeiro: Lucerna.

Ohta, A.S. (2000). Rethinking interaction in SLA: Developmentally appropriate assistance in the Zone of Proximal Development and the acquisition of L2 grammar. Lantolf (ed.). 
Paltridge, B. (2001). Genre and the language learning classroom. Ann Arbor: University of Michigan Press.

Santos, V. B.M.P. (1998). Estabelecendo as diferenças entre os termos "registro" e "gênero". The ESPecialist, 19 (1), 1-40. . (2002). Genre analysis of business letters of negotiation. English for Specific Purposes, 21 (2), 167-199.

Swales, J. M. (1990). Genre analysis: English in academic and research settings. Cambridge: Cambridge University Press.

\begin{abstract}
A AUTORA
Isabela Gomes Bustamante possui graduação em Letras (Inglês/Literaturas) pela Universidade do Estado do Rio de Janeiro (1999), Especialização em Língua Inglesa pela Universidade do Estado do Rio de Janeiro (2001) e é mestranda em Estudos da Linguagem na Pontifícia Universidade Católica do Rio de Janeiro. Atualmente é professora de inglês da Sociedade Brasileira de Cultura Inglesa do Rio de Janeiro. Tem experiência na área de Letras, com ênfase no Ensino de Inglês como Língua Estrangeira. E-mail: belabustamante@gmail.com.
\end{abstract}

